\title{
Dramatic response to alectinib in a lung cancer patient with a novel VKORCILI-ALK fusion and an acquired ALK TI I IIK mutation
}

This article was published in the following Dove Press journal: Lung Cancer:Targets and Therapy

\author{
Viola W Zhu' \\ Alexa B Schrock ${ }^{2}$ \\ Thangavijayan Bosemani ${ }^{3}$ \\ Bryan S Benn ${ }^{4}$ \\ Siraj M Ali \\ Sai-Hong Ignatius $\mathrm{Ou}$ \\ 'Chao Family Comprehensive Cancer \\ Center, Division of Hematology/ \\ Oncology, Department of Medicine, \\ University of California, Irvine School \\ of Medicine, Orange, CA, USA; \\ ${ }^{2}$ Clinical Development, Foundation \\ Medicine, Inc., Cambridge, MA, USA; \\ ${ }^{3}$ Department of Radiological Sciences, \\ University of California, Irvine School \\ of Medicine, Orange, CA, USA; \\ ${ }^{4}$ Division of Pulmonary Diseases and \\ Critical Care Medicine, Department \\ of Medicine, University of California, \\ Irvine School of Medicine, Orange, \\ CA, USA
}

\begin{abstract}
A L K$-rearranged lung cancer defines a distinctive molecular cohort of patients whose outcomes are significantly improved by the availability of ALK inhibitors. Thus, it is imperative for clinicians to screen appropriate patients for this driver mutation with a molecular testing platform capable of capturing all ALK fusions. Here, we report a novel VKORC1L1-ALK fusion and an ALK T1151K resistance mutation detected in a lung cancer patient who had been on crizotinib for over 8 years. Alectinib induced a dramatic response in this patient demonstrating its clinical activity against $\mathrm{T} 1151 \mathrm{~K}$. This case illustrates the importance of performing repeat biopsy to explore mechanism(s) of resistance when patients experience disease progression on an ALK inhibitor. The approach has a direct therapeutic impact particularly when an ALK resistance mutation is identified.
\end{abstract}

Keywords: VKORC1L1, T1151, fusion, resistance, crizotinib, lorlatinib

\section{Introduction}

In the US, there are now four approved ALK inhibitors for patients with metastatic $A L K$-rearranged lung cancer and many more at various development stages. Because of significant clinical benefits these ALK inhibitors provide, it is imperative for clinicians to screen appropriate patients for this driver mutation with a molecular testing platform capable of capturing all $A L K$ fusions. For patients who progress on an ALK inhibitor, performing repeat biopsy to look for mechanism(s) of resistance is highly recommended. Identifying an ALK resistance mutation may guide selection of another ALK inhibitor with known activity against the specific mutation. Here, we report a novel VKORC1L1-ALK fusion with an acquired ALK T1151K resistance mutation detected in a patient who had disease progression after being on crizotinib for over 8 years. He had a dramatic response to alectinib illustrated in the following narrative indicating that $\mathrm{T} 1151 \mathrm{~K}$ confers sensitivity to alectinib.

\section{Case presentation}

A 54-year-old Caucasian man, former smoker of $<5$ pack years, originally underwent resection for locally advanced adenocarcinoma of the lung in April 2006 followed by adjuvant chemoradiation with weekly carboplatin/paclitaxel for focally positive margin. He was found to have metastatic disease in his pelvis in November 2008 for which he received palliative radiation. In October 2009, a computed tomography (CT) scan performed for cough showed multiple bilateral subcentimeter lung nodules and a large left pleural effusion. However, the patient had elected not to receive any treatment
Chao Family Comprehensive Cancer Center, Division of Hematology/ Oncology, Department of Medicine, University of California, Irvine School of Medicine, I0I The City Drive South, Orange, CA 92868, USA

Tel + I 7144568105

Fax +I 7144566179

Email zhurw@uci.edu 
until February 2010 when he presented to our cancer center to discuss participation in clinical trial. The molecular profiling performed at the Massachusetts General Hospital revealed an ALK rearrangement, so he was enrolled in the PROFILE 1001 study (NCT00585195) in March 2010. He had a sustained partial response (PR, $-27 \%$ by RECIST 1.1 ) to crizotinib at $250 \mathrm{mg}$ twice daily confirmed by a contrast CT scan in October 2012. He declined further scans afterwards, and so he was switched to commercial supply of crizotinib in February 2013.

In April 2018, the patient developed dry cough while on crizotinib for which a contrast CT scan of the chest was performed that showed complete opacification of the left hemithorax (Figure 1). Restaging scans confirmed disease progression in both lungs, thoracic lymph nodes, pleura, and bone. He was immediately switched to alectinib at $600 \mathrm{mg}$ twice daily while comprehensive genomic profiling (CGP) via Foundation Medicine, Inc. (Cambridge, MA, USA) was performed on a plasma-based liquid biopsy which subsequently identified a novel $V K O R C 1 L 1-A L K$ fusion as well as an ALK T1151K resistance mutation. This CGP assay covers 62 genes to $\times 5,000$ unique coverage and includes intron baiting for rearrangements of six genes ( $A L K, E G F R, F G F R 3$, $P D G F R-\alpha, R O S 1$, and RET). Alectinib was continued based on predicted efficacy of this ALK inhibitor against T1151K. A follow-up contrast CT scan of the chest 14 weeks later showed a dramatic response ( $-76 \%$ by RECIST 1.1$)$ including resolution of a $2.9 \mathrm{~cm}$ left paravertebral mass at T1-2 level, decrease in size of the right pulmonary nodule from 1.8 to $1.1 \mathrm{~cm}$, and significant improvement of the left lung aeration (Figure 1). Of note, prior to this follow-up scan, the patient underwent endobronchial cryosurgery for tissue extraction and spray cryotherapy of an endobronchial mass in order to prevent any significant pulmonary hemorrhage and for airway recanalization, but we did not obtain enough tissue for CGP. At the time of this manuscript preparation, the patient has been on alectinib for over 23 weeks with no reported symptoms. A written informed consent was obtained to have the case details published, and institutional approval was not required to publish this case report.

\section{Discussion}

We believe this is the first report of $V K O R C 1 L 1-A L K$ fusion detected in a lung cancer patient. Ever since the discovery of the transforming $E M L 4-A L K$ fusion gene by Soda and Rikova et al in 2007, various $A L K$ fusion partners have been identified including TFG, KIF5B, KCL1, PTPN3, STRN, HIP1, TPR, BIRC6, DCTN1, SQSTM1, SOCS5, CLIP4, CLTC, PRKAR1A, PPM1B, EIF2AK3, CRIM1, GCC2,
DYSF, ITGAV, VIT, PLEKHA7, and $C U X 1 .{ }^{1-19} \mathrm{~A}$ list of chronologically published fusion partners in $A L K$-rearranged lung cancer with references is summarized in Table 1 . The VKORC1L1 gene encodes an enzyme known as vitamin $\mathrm{K}$ 2,3-epoxide reductase, whose catalytic function is critical for the vitamin $\mathrm{K}$ cycle. The vitamin $\mathrm{K}$-dependent proteins have various physiological roles that are not just restricted to coagulation and hemostasis. Although little is known of the functions of these proteins in direct tumorigenesis, they may contribute to remodeling of tumor microenvironment as vascular endothelial cell survival depends on vitamin $\mathrm{K}$. In addition, the mRNA and protein expressions of VKORC1L1 in lung have been reported..$^{20}$ The $V K O R C 1 L 1$ gene is located on chromosome 7q11.21 and only contains three exons with 531 nucleotides. The encoded protein product has 176 amino acids (aa) with four endoplasmic reticulum transmembrane domains. In this case, exon 1 of VKORC1L1 (aa 1-64) was fused with exons 20-29 (aa 1058-1620) of the $A L K$ gene generating the final fusion protein which contains the full ALK tyrosine kinase domain (aa 1116-1329) (Figure 2). Interestingly, our patient's tumor was found to harbor $A L K$ rearrangement in 2010, but the specific fusion partner could not be identified by fluorescence in situ hybridization at the time.

The other significance of this report is the demonstration of the sensitivity of the ALK T1151K resistance mutation to alectinib in a clinical patient case. The identification of $\mathrm{T} 1151 \mathrm{~K}$ as a resistance mutation to crizotinib was reported in 2011 by Zhang et al through an accelerated mutagenesis screen. ${ }^{21}$ Our group was the first to report this resistance mutation in an $A L K$-rearranged lung cancer patient with prior exposure to crizotinib and ceritinib. Based on co-crystal structures of ceritinib/ALK, alectinib/ALK, and lorlatinib/ ALK, we concluded that $\mathrm{T} 1151 \mathrm{~K}$ confers resistance to ceritinib which may be rescued by alectinib or lorlatinib. We also speculated that brigatinib may not be able to completely overcome the $\mathrm{T} 1151 \mathrm{~K} / \mathrm{M}$ resistance mutations according to an in vitro assay as well as the strong interaction of brigatinib with the P-loop of the ALK protein which may be interrupted by the T1151 mutation leading to drug resistance. ${ }^{22}$ The patient described in our previous case report has been on lorlatinib for over two years with a PR ( $-32 \%$ by RECIST 1.1$)$. The dramatic response seen in this case would require longer follow-up to determine if the response is durable. Interestingly, as alectinib only has weak interaction with the P-loop of the ALK protein while lorlatinib has moderate interaction, alectinib may be more potent than lorlatinib to rescue patients with tumors harboring the ALK T1151K resistance mutation, 

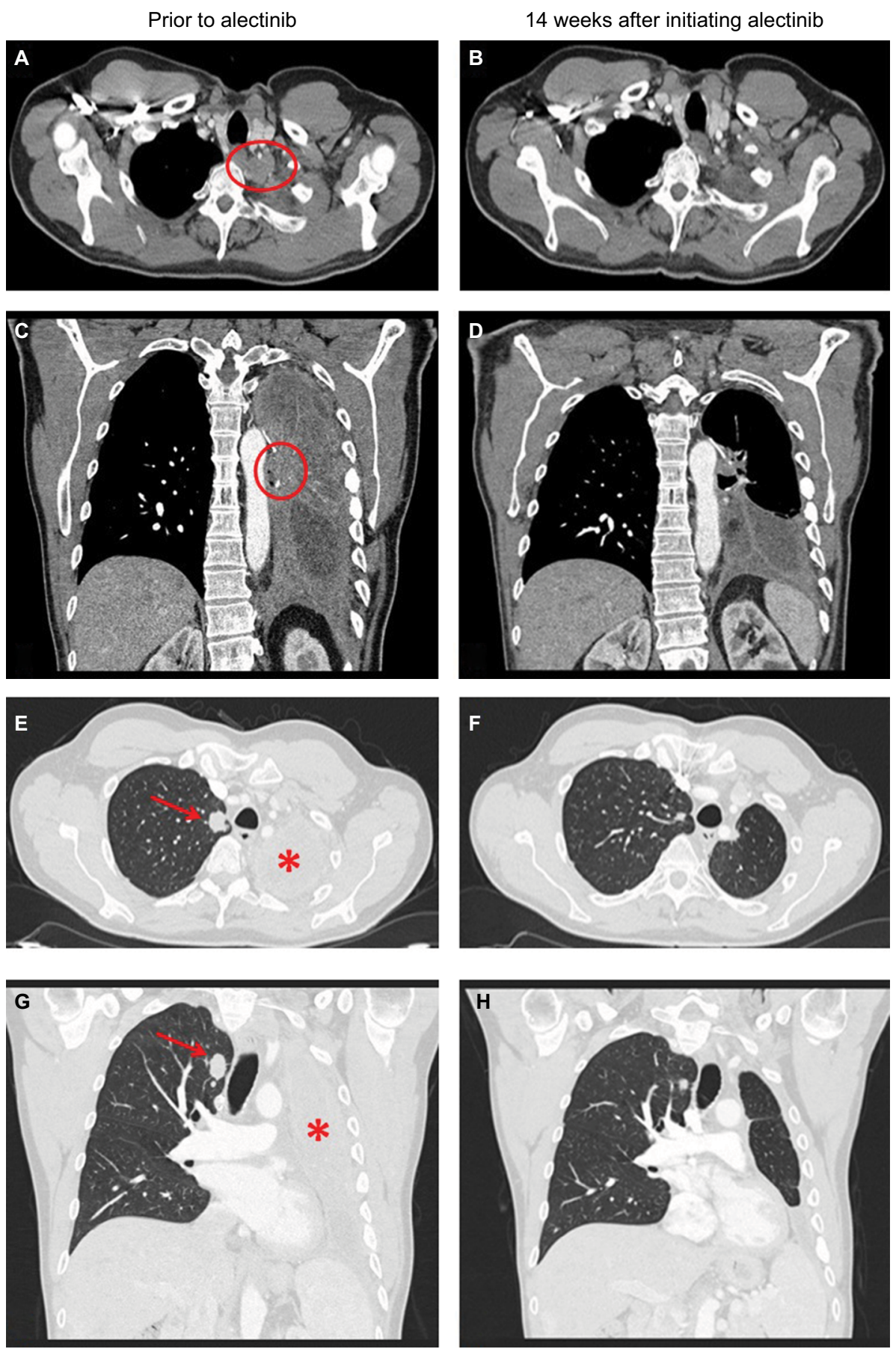

Figure I Contrast CT scans of the chest showing a left paravertebral mass at TI-2 level (indicated by a red circle) prior to use of alectinib (A and $\mathbf{C}$ ) and resolution of this mass 14 weeks after initiating alectinib (B and D). Contrast CT scans of the chest showing decrease in size of the right pulmonary nodule (indicated by a red arrow) and significant improvement of the left lung aeration (indicated by a red star) I4 weeks after initiating alectinib (F and $\mathbf{H})$ as compared with prior to use of alectinib (E and $\mathbf{G})$. Abbreviation: CT, computed tomography.

which could explain a greater response seen in this patient treated with alectinib.

One limitation of this case report is that from a molecular standpoint it remains unclear how the ALK protein is activated by its fusion partner VKORC1L1 as this protein product does not appear to contain a dimerization domain similar to EML4. It would be ideal to demonstrate positive ALK immunohistochemistry or the final VKORC1L1ALK fusion protein and phospho-ALK by Western blot for instance. However, our patient declined tissue biopsy and 
Table I Published fusion partners in ALK-rearranged lung cancer

\begin{tabular}{|c|c|c|}
\hline Number & Fusion partner & Reference(s) \\
\hline 1 & EML4 & Soda et al, Nature 2007'; Rikova et al, Cell $2007^{2}$ \\
\hline 2 & TFG & Rikova et al, Cell $2007^{2}$ \\
\hline 3 & KIF5B & Takeuchi et al, Clin Cancer Res $2009^{3}$ \\
\hline 4 & $\mathrm{KCLI}$ & Togashi et al, PLoS One $2012^{4}$ \\
\hline 5 & PTPN3 & Jung et al, Genes Chromosomes Cancer $2012^{5}$ \\
\hline 6 & STRN & Majewski et al, J Pathol 20136 \\
\hline 7 & HIPI & Fang et al, J Thorac Oncol 20147; Hong et al, J Thorac Oncol $2014^{8}$ \\
\hline 8 & TPR & Choi et al, J Thorac Oncol $2014^{9}$ \\
\hline 9 & $\mathrm{BIRC} 6$ & Shan et al, J Thorac Oncol $2015^{10}$ \\
\hline 10 & DCTNI & lyevleva et al, Cancer Lett 2015"I \\
\hline 11 & SQSTMI & lyevleva et al, Cancer Lett 2015"1 \\
\hline 12 & SOCS5 & Drilon et al, Clin Cancer Res $2015^{12}$ \\
\hline 13 & CLIP4 & Drilon et al, Clin Cancer Res $2015^{12}$ \\
\hline 14 & CLTC & Ali et al, Oncologist $2016^{13}$ \\
\hline 15 & PRKARIA & Ali et al, Oncologist $2016^{13}$ \\
\hline 16 & PPMIB & Ali et al, Oncologist $2016^{13}$ \\
\hline 17 & EIF2AK3 & Ali et al, Oncologist $2016^{13}$ \\
\hline 18 & CRIMI & Tan et al, J Clin Oncol $2016^{14}$ \\
\hline 19 & GCC2 & Jiang et al, Lung Cancer $2018^{15}$ \\
\hline 20 & DYSF & Yin et al, J Thorac Oncol $2018^{16}$ \\
\hline 21 & ITGAV & Yin et al, J Thorac Oncol $2018^{16}$ \\
\hline 22 & VIT & Hu et al, J Thorac Oncol $2018^{17}$ \\
\hline 23 & PLEKHA7 & Schrock et al, J Thorac Oncol $2018^{18}$ \\
\hline 24 & CUXI & Zhang et al, J Thorac Oncol $2018^{19}$ \\
\hline 25 & VKORCILI & This case* \\
\hline
\end{tabular}

Notes: *This fusion partner was detected in conjunction with an acquired ALK resistance mutation.

VKORC1L1 exon 1 (aa 1-64) ALK exons 20-29 (aa 1058-1620)

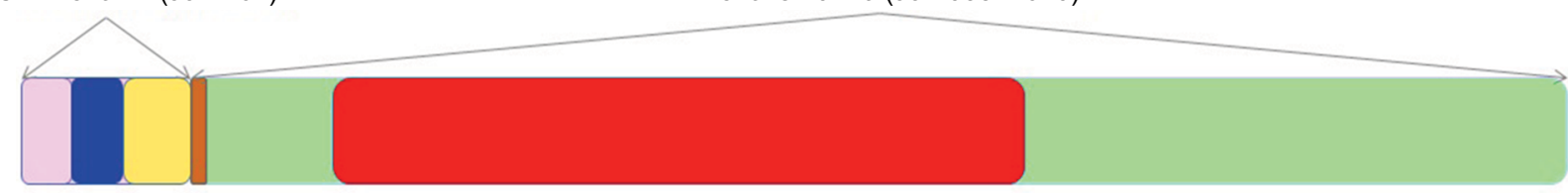

Cytoplasmic domain (aa 1-16)

Transmembrane domain (aa 1058-1059)

Transmembrane domain (aa 17-37)

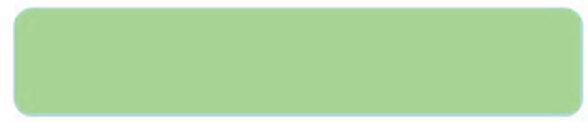

Cytoplasmic domain (aa 1060-1620)

Luminal domain (aa 38-64)

Tyrosine kinase domain (aa 1116-1329)

Figure 2 Schema of the VKORCILI-ALK fusion protein.

Notes: The VKORCILI gene only contains three exons with 531 nucleotides. The encoded protein product has 176 aa with four endoplasmic reticulum transmembrane domains (aa 17-37, aa 92-I I2, aa I 14-I34, and aa I35-155). In this case, exon I of VKORCILI (aa I-64) is fused with exons 20-29 (aa 1058-1620) of the ALK gene generating the final fusion protein which contains the full ALK tyrosine kinase domain (aa II I6-1329). Of note, the luminal domain of the VKORCILI protein itself contains aa 38-9I, but the final VKORCILI-ALK fusion protein only contains aa 38-64 which is highlighted in yellow. Similarly, the transmembrane domain of the ALK protein itself contains aa 1039-1059, but the final VKORCILI-ALK fusion protein only contains aa 1058-1059 which is highlighted in brown.

Abbreviation: aa, amino acid.

his therapeutic bronchoscopy did not yield enough tissue to perform such laboratory assays. It is fortunate that liquid biopsy revealed this novel $A L K$ fusion and an acquired ALK resistance mutation. More importantly, the dramatic response seen in follow-up scans highly suggests that his disease process remains dependent on the ALK signaling pathway.

The patient will undergo routine CT scans to monitor treatment response as well as surveillance brain magnetic 
resonance imaging as it is a common site of disease progression for patients with $A L K$-rearranged lung cancer. He does not have any brain metastasis at present. Should his disease progress again, we plan to explore resistance mechanism(s) by repeat biopsy. As patients are exposed to sequential ALK inhibitors, they are more likely to develop compound ALK resistance mutations. This phenomenon has been elegantly illustrated by Yoda et al in their approach to define lorlatinibresistant ALK mutations. ${ }^{23}$ To prevent highly refractory compound mutations from emerging, one might argue for the upfront use of the most potent ALK inhibitor and designing next-generation ALK inhibitors that can overcome these resistance mutations.

\section{Conclusion}

$A L K$-rearranged lung cancer defines a distinctive molecular cohort of patients whose outcomes are significantly improved by the availability of ALK inhibitors. Thus, screening for this driver mutation by a comprehensive molecular testing platform is absolutely necessary in routine practice. This is the first case report of a novel VKORC1L1-ALK fusion detected in a lung cancer patient. The patient had been on crizotinib for over 8 years until emergence of an ALK T1151K resistance mutation that was successfully treated with alectinib, demonstrating for the first time the activity of alectinib against $\mathrm{T} 1151 \mathrm{~K}$ in the clinic.

\section{Disclosure}

VWZ has received honoraria from Roche-Foundation Medicine, Roche/Genentech, Takeda, and Biocept, and consulting fees from TP Therapeutics. ABS and SMA are employees of Foundation Medicine, Inc., a wholly owned subsidiary of Roche. SIO has received honoraria from Pfizer, RocheFoundation Medicine, Roche/Genentech, and Takeda, and has stock ownership in TP Therapeutics. The other authors report no conflicts of interest in this work.

\section{References}

1. Soda M, Choi YL, Enomoto M, et al. Identification of the transforming $E M L 4-A L K$ fusion gene in non-small-cell lung cancer. Nature. 2007;448(7153):561-566.

2. Rikova K, Guo A, Zeng Q, et al. Global survey of phosphotyrosine signaling identifies oncogenic kinases in lung cancer. Cell. 2007;131(6):1190-1203.

3. Takeuchi K, Choi YL, TogashiY, et al. KIF5B-ALK, a novel fusion oncokinase identified by an immunohistochemistry-based diagnostic system for ALK-positive lung cancer. Clin Cancer Res. 2009;15(9):3143-3149.
4. Togashi Y, Soda M, Sakata S, et al. KLC1-ALK: a novel fusion in lung cancer identified using a formalin-fixed paraffin-embedded tissue only. PLoS One. 2012;7(2):e31323.

5. Jung Y, Kim P, Jung Y, et al. Discovery of $A L K-P T P N 3$ gene fusion from human non-small cell lung carcinoma cell line using next generation RNA sequencing. Genes Chromosomes Cancer. 2012;51(6):590-597.

6. Majewski IJ, Mittempergher L, Davidson NM, et al. Identification of recurrent FGFR3 fusion genes in lung cancer through kinome-centred RNA sequencing. J Pathol. 2013;230(3):270-276.

7. Fang DD, Zhang B, Gu Q, et al. HIP1-ALK, a novel ALK fusion variant that responds to crizotinib. J Thorac Oncol. 2014;9(3):285-294.

8. Hong M, Kim RN, Song JY, et al. HIP1-ALK, a novel fusion protein identified in lung adenocarcinoma. J Thorac Oncol. 2014;9(3):419-422.

9. Choi YL, Lira ME, Hong M, et al. A novel fusion of TPR and ALK in lung adenocarcinoma. J Thorac Oncol. 2014;9(4):563-566.

10. Shan L, Jiang P, Xu F, et al. BIRC6-ALK, a novel fusion gene in ALK break-apart FISH-negative lung adenocarcinoma, responds to crizotinib. J Thorac Oncol. 2015;10(6):e37-e39.

11. Iyevleva AG, Raskin GA, Tiurin VI, et al. Novel $A L K$ fusion partners in lung cancer. Cancer Lett. 2015;362(1):116-121.

12. Drilon A, Wang L, Arcila ME, et al. Broad, hybrid capture-based next-generation sequencing identifies actionable genomic alterations in "driver-negative" lung adenocarcinomas. Clin Cancer Res. 2015;21:3631-3639.

13. Ali SM, Hensing T, Schrock AB, et al. Comprehensive genomic profiling identifies a subset of crizotinib-responsive $A L K$-rearranged non-small cell lung cancer not detected by fluorescence in situ hybridization. Oncologist. 2016;21(6):762-770.

14. Tan DS, Kim DW, Thomas M, et al. Genetic landscape of ALK+ nonsmall cell lung cancer (NSCLC) patients (pts) and response to ceritinib in ASCEND-1. J Clin Oncol. 2016;34(suppl; abstr 9064).

15. Jiang J, Wu X, Tong X, et al. GCC2-ALK as a targetable fusion in lung adenocarcinoma and its enduring clinical responses to ALK inhibitors. Lung Cancer. 2018;115:5-11.

16. Yin J, Zhang Y, Zhang Y, Peng F, Lu Y. Reporting on two novel fusions, $D Y S F-A L K$ and $I T G A V-A L K$, coexisting in one patient with adenocarcinoma of lung, sensitive to crizotinib. $J$ Thorac Oncol. 2018;13(3):e43-e45.

17. Hu S, Li Q, Peng W, et al. VIT-ALK, a novel alectinib-sensitive fusion gene in lung adenocarcinoma. J Thorac Oncol. 2018;13(5):e72-e74.

18. Schrock AB, Zhu VW, Hsieh WS, et al. Receptor tyrosine kinase fusions and BRAF kinase fusions are rare but actionable resistance mechanisms to EGFR tyrosine kinase inhibitors. J Thorac Oncol. 2018;13(9):1312-1323.

19. Zhang M, Wang Q, Ding Y, et al. $C U X 1-A L K$, a Novel $A L K$ Rearrangement That Responds to Crizotinib in Non-Small Cell Lung Cancer. J Thorac Oncol. Epub 2018 Aug 7.

20. Oldenburg J, Watzka M, Bevans CG. VKORC1 and VKORC1L1: Why do Vertebrates Have Two Vitamin K 2,3-Epoxide Reductases? Nutrients. 2015;7(8):6250-6280.

21. Zhang S, Wang F, Keats J, et al. Crizotinib-resistant mutants of EML4ALK identified through an accelerated mutagenesis screen. Chem Biol Drug Des. 2011;78(6):999-1005.

22. Zhu VW, Cui JJ, Fernandez-Rocha M, Schrock AB, Ali SM, Ou SI. Identification of a novel T1151K $A L K$ mutation in a patient with $A L K$ rearranged NSCLC with prior exposure to crizotinib and ceritinib. Lung Cancer. 2017;110:32-34.

23. Yoda S, Lin JJ, Lawrence MS, et al. Sequential $A L K$ Inhibitors Can Select for Lorlatinib-Resistant Compound $A L K$ Mutations in $A L K$-Positive Lung Cancer. Cancer Discov. 2018;8(6):714-729. 


\section{Publish your work in this journal}

Lung Cancer: Targets and Therapy is an international, peer-reviewed, open access journal focusing on lung cancer research, identification of therapeutic targets and the optimal use of preventative and integrated treatment interventions to achieve improved outcomes, enhanced survival and quality of life for the cancer patient. Specific topics covered in the journal include: Epidemiology, detection and screening; Cellular research and biomarkers; Identification of biotargets and agents with novel published authors.

mechanisms of action; Optimal clinical use of existing anticancer agents, including combination therapies; Radiation and surgery; Palliative care; Patient adherence, quality of life, satisfaction; Health economic evaluations. The manuscript management system is completely online and includes a very quick and fair peer-review system. Visit http://www.dovepress.com/testimonials.php to read real quotes from

Submit your manuscript here: https://www.dovepress.com/lung-cancer-targets--therapy-journal 